\title{
Preliminary Analysis of the Use of Construction Waste to Replace Conventional Aggregates in Concrete
}

\author{
Fernando A. N. Silva ${ }^{1}$, João M. P. Q. Delgado ${ }^{2, * \mathbb{D}}$, António C. Azevedo ${ }^{2}\left(\mathbb{D}\right.$, António G. B. Lima ${ }^{3} \mathbb{D}$ \\ and Castorina $S$. Vieira ${ }^{2}$ \\ 1 Departamento de Engenharia Civil, Universidade Católica de Pernambuco, Recife, PE 50050-900, Brazil; \\ fernando.nogueira@unicap.br \\ 2 CONSTRUCT, Department of Civil Engineering, Faculty of Engineering, University of Porto, \\ 4200-465 Porto, Portugal; antonio.costaazevedo@fe.up.pt (A.C.A.); cvieira@fe.up.pt (C.S.V.) \\ 3 Department of Mechanical Engineering, Federal University of Campina Grande, \\ Campina Grande, PB 58429-900, Brazil; antonio.gilson@ufcg.edu.br \\ * Correspondence: jdelgado@fe.up.pt; Tel.: +35-12-2508-1404
}

check for

updates

Citation: Silva, F.A.N.; Delgado, J.M.P.Q.; Azevedo, A.C.; Lima, A.G.B.; Vieira, C.S. Preliminary Analysis of the Use of Construction Waste to Replace Conventional Aggregates in Concrete. Buildings 2021, 11, 81. https://doi.org/10.3390/ buildings11030081

Academic Editor:

Francesco Colangelo

Received: 26 January 2021

Accepted: 22 February 2021

Published: 25 February 2021

Publisher's Note: MDPI stays neutral with regard to jurisdictional claims in published maps and institutional affiliations.

Copyright: (c) 2021 by the authors Licensee MDPI, Basel, Switzerland. This article is an open access article distributed under the terms and conditions of the Creative Commons Attribution (CC BY) license (https:/ / creativecommons.org/licenses/by/ $4.0 /)$.

\begin{abstract}
This work aims to study the influence of using construction and demolition waste in the replacement of coarse and fine aggregate to produce recycled aggregate concrete (RAC). A moderate compressive strength concrete made with usual fine and coarse aggregate was used as a benchmark material. Compressive and split tensile tests were performed using 120 cylindrical concrete specimens with $150 \mathrm{~mm}$ diameter and $300 \mathrm{~mm}$ length. Four-point flexural tests in reinforced beams made with conventional concrete and RAC were performed. The results obtained showed that the use of recycled fine aggregates, in both percentages of substitution investigated-50\% and $100 \%$ - did not generate any deleterious influence on the values of compressive strength and split tensile strength of the RACs produced. Tin fact, the mechanical strengths of RACs produced with recycled fine aggregate were equal or higher than those from the reference concrete. The same behavior was not observed, however, when the recycled coarse aggregate was used. For this case, decreases in concrete mechanical strengths were observed, especially in compressive strength, with values around $35 \%$ lower when compared to the reference concrete. Tensile mechanical tests results confirmed the excellent behavior of all RACs made with replacement of usual fine aggregates by recycled. Bending tests performed in reinforced RAC beams had as objective to evaluate the deformation profile of the beams. The obtained results showed that RAC beams with full replacement of usual fine aggregate by the recycled aggregates have presented little changes in the global behavior, an aspect that encourages its use.
\end{abstract}

Keywords: sustainable construction; recycled aggregate concrete; construction waste; recycled aggregates

\section{Introduction}

Urban development around the world, combined with inefficient management of public and private spaces plays an important role in the generation of construction and demolition waste (CDW). In the same direction, the increase in the use of concrete and the consumption of natural resources to produce its raw material a process that demands large amounts of energy can lead to the depletion of natural aggregates [1-3]. CDW is usually discarded in nature through an inadequate process, sometimes polluting natural resources, and this fact is already an aspect that has been causing major problems for metropolises worldwide.

Global demand for construction aggregates is forecast to rise by about $2.5 \%$ per year to approximately 48 billion metric tons in 2023 [4]. This demand can be explained by several facts, among which stand out the continued strong growth in global construction activity, the rebound in global cement demand to build necessary infrastructure in several underdeveloped countries around the world [5]. This scenario points to the need to develop 
research to find technically and financially sustainable alternatives for the use of CDW. When one observes that the use of CDW is very incipient in most continents on the planet, representing less than $5 \%$ of worldwide aggregate demand [6,7], it becomes clear the great potential of this emerging market.

Recycled aggregate concrete (RAC), produced with partial or total replacement of natural aggregates by recycled aggregates in the concrete mix, has been shown to provide significant environmental benefits and economic benefits, such as the decrease of the consumption of natural resources and of the volume of waste sent to dumping grounds [8,9]. However, RAC has to be seen as a secondary material with quality inferior to usual aggregates used to produce despite its countless environmental advantages [10].

Compressive strength obtained through standard tests to access concrete properties is considered as an important indicator of normal aggregates concretes quality and can also be used to get an approximate value for other properties, i.e., young's modulus, flexural and tensile strengths, when specific tests are not available.

Most of recent researches on the use of recycled aggregate concrete as partial or full replacement of natural aggregates to produce concrete highlights that this approach is a promising technology for conserving natural resources and reducing the environmental impact of concrete.

Ozbakkaloglu et al. [1] investigated the effect of recycled aggregates with different sizes and contents on the mechanical and durability properties of concrete made from 14 baths -3 ones of using natural aggregate concrete and 11 using RA. The recycled aggregates used contained $97 \%$ concrete aggregates and 3\% brick aggregates by mass. This type of aggregates is not the most common aggregate found in usual construction and demolition waste. Authors also reported the use of concrete of pozzolanic admixture and superplasticizer to improve RAC quality. Three small unreinforced beams$100 \times 100 \times 500 \mathrm{~mm}^{3}$ - were tested for each mixture to assess concrete flexural strengths to compare with splitting tensile strengths was performed in standard specimens. The authors reported that compressive strength should not be the only factor regarding the mechanical and durability of RACs and the size and the amount of coarse aggregate play an important role.

Ulloa et al. [11] studied the effect of the use of recycled coarse aggregates from previous concrete structures on compressive strength and its evolution through time. Authors concluded that that effective $\mathrm{w} / \mathrm{c}$ and replacement ratio determine compressive strength, but their effects upon it are significantly modified by the properties and composition of the aggregates used. They also concluded that both the replacement ratio and the type of aggregate used play important role in the compressive strength of RACs but their effect is significantly modified by the properties and composition of the recycled aggregates used.

Atmajayanti et al. [12] investigated the concrete mechanical properties using RCA made with recycled coarse aggregate with an acrylic-based material applied in its surface. The idea to use this surface treatment was to reduce the water absorption rate of the coarse aggregate to improve the mechanical properties of RAC made with it. Authors reported a reduction de $63 \%$ in aggregate water absorption with direct influence in the concrete mechanical properties. Two amounts of recycled coarse aggregates were investigated-50 and $100 \%$ - and some small increase in compressive strength, tensile strength, and modulus of elasticity of RACs studied was reported.

Khatib [13] studied RACs made with fine recycled aggregates from crushed concrete or crushed brick with particles size less than $5 \mathrm{~mm}$ in diameter. Fine aggregate in concrete was replaced with $0 \%, 25 \%, 50 \%$, and $100 \%$ of crushed concrete and brick. Nine different concrete mixtures were investigated and the free water/cement ratio was kept constant for all mixtures. Authors reported a systematic reduction in long-term strength about $30 \%$ for a replacement level of $100 \%$ of usual fine aggregate by recycled aggregate from crushed concrete. The same behavior was not observed when the replacement of usual fine aggregate was made by fine aggregates from crushed brick. Is this case, no influence in long term strength was reported. The authors suggested that this behavior can be attributed 
to the pozzolanic reaction caused by the silica and alumina contents of crushed brick fine aggregates and the product of cement hydration-portlandite).

Others studies $[1,14-16]$ have shown that the relationships between compressive strength and other mechanical factors and properties related to the durability on RAC vary with the rate of substitution of the recycled aggregate.

In general, the use of CDW is focused mainly on the issues regarding the technical development of the material with insights on the environmental impacts of the process. However, the emphasis on market viability is a commitment to the effectiveness of research, since the social benefits of a research process will only be fully realized if the new product produced generates jobs, reduces the volume of landfills, consumes waste in instead of natural resources and avoid contamination of the environment or compromise the health of the population [17].

In resume, the evaluation of the use of CDW in the construction sector has been stimulated in several parts of the world and many studies have been developed to increase knowledge about the behavior of these residues for the production of new materials. This work aims to study the influence of using construction and demolition waste as replacements of usual coarse and fine aggregate often used to produce concrete and to evaluate their influence over the compression and tension strengths of the material as well as the overall profile deformation of reinforced RAC beams made with CDW investigated. This latter constitutes one important contribution of the paper taken into account the few availability of lab tests in reinforced concrete flexural element made with fine and coarse recycled aggregate from constructions and demolition waste.

\section{Materials and Methods}

In this work, construction and demolition waste was used to produce both fine and coarse recycled aggregated (RA) in replacement to usual aggregate to produce concrete. The waste used came from a civil construction recycling plant and its composition contains materials from several origins like excavation residues, demolition of simple and reinforced concrete elements, the residue of ceramic masonry materials—bricks and tiles_-and also mortar cement-based bricks and mortars. Before processing the RA, an initial manual separation was carried out to remove materials such as wood, plastic, and plaster. The material is, then, taken to a RA recycling plant where it begins its processing that can be summarized as it follows: (a) feeding and pre-screening, (b) aggregate scrubbing, (b) contaminant removal, (c) metals and others undesirable materials removal, (d) sand washing, (e) aggregate sizing, (f) primary stage water treatment, and (g) deposited in bags according to their granulometry. Figure 1 shows a general view of the RA recycling plant.

\subsection{Physical Characterization Tests}

Table 1 shows the results of physical characterization and Figure 2 exhibits the size distribution profile for usual aggregate and both, fine and coarse aggregates, obtained from the processing of the RA investigated.

Table 1. Physical properties of aggregates used.

\begin{tabular}{ccccc}
\hline \multirow{2}{*}{ Test } & \multicolumn{2}{c}{ Fine Aggregate } & \multicolumn{2}{c}{ Coarse Aggregate } \\
\cline { 2 - 5 } & Usual & RA & Usual & RA \\
\hline Specific gravity $\left(\mathrm{g} / \mathrm{cm}^{3}\right)$ & 2.65 & 2.50 & 2.54 & 2.32 \\
\hline Water absorption rate $(\%)$ & - & - & 0.30 & 3.51 \\
\hline Fineness modulus $(-)$ & 2.07 & 1.90 & - & 6.97 \\
\hline
\end{tabular}




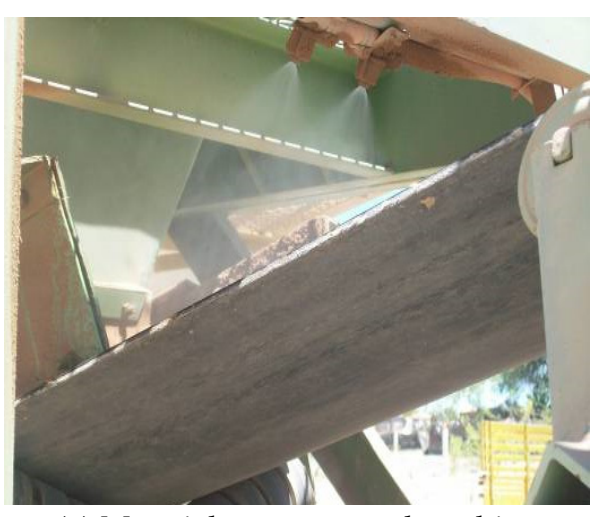

(a) Material transport and washing

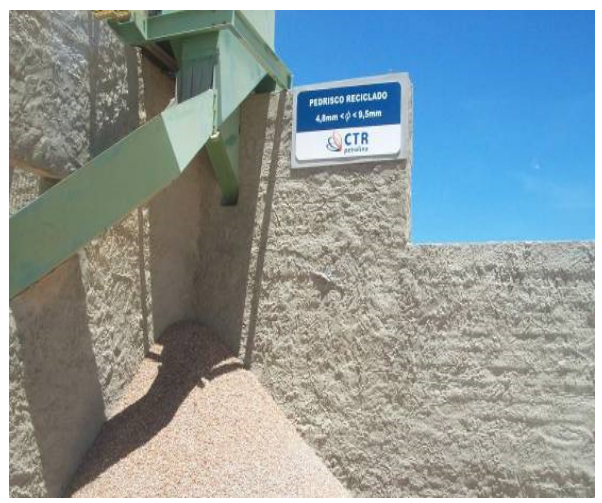

(c) Fine aggregate obtained

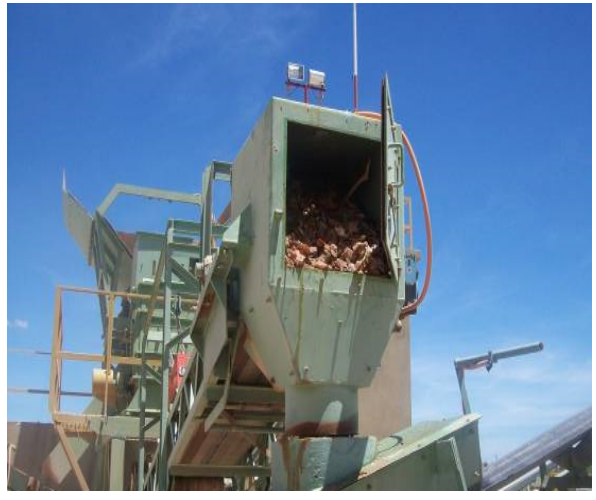

(b) Final stage of the process

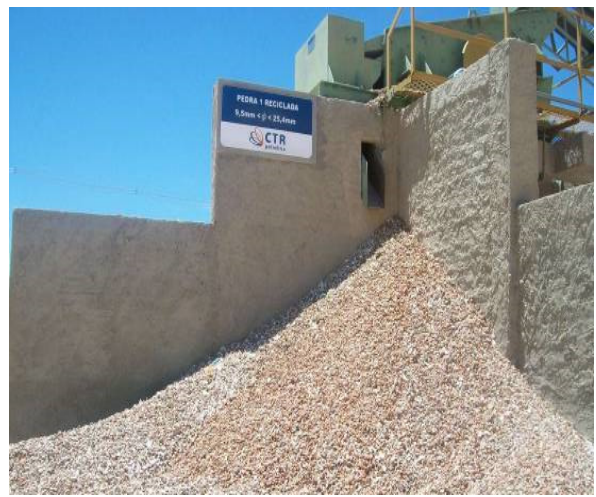

(d) Coase aggregate obtained

Figure 1. Overview of a RA recycling plant.

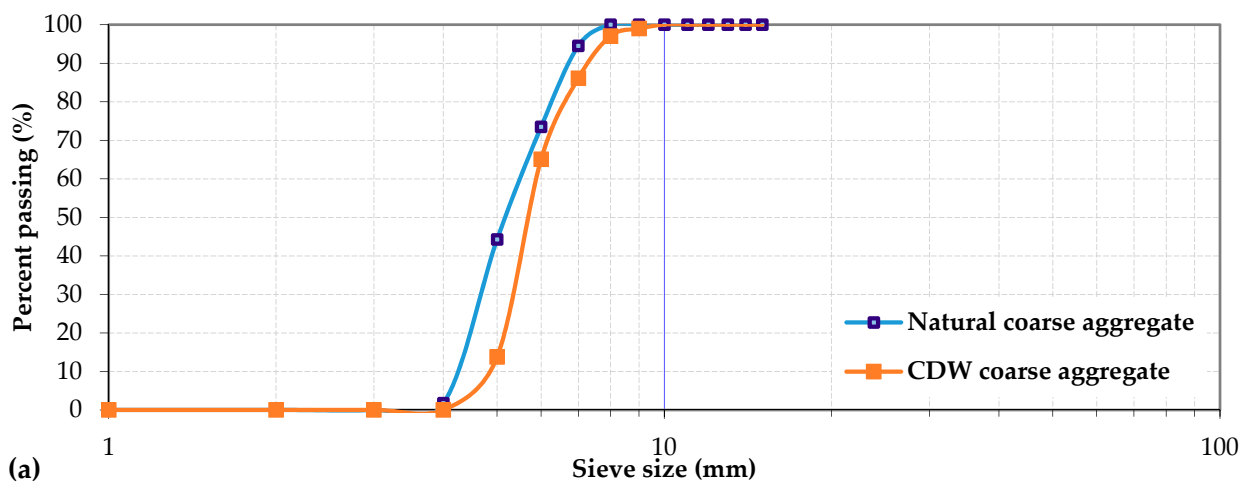

(a)

Sieve size (mm)

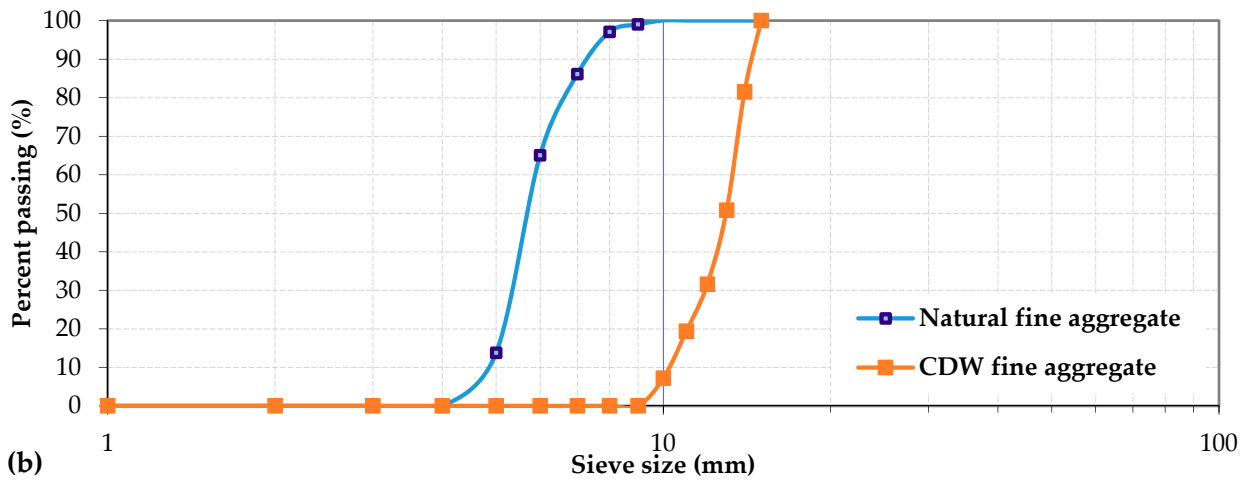

Figure 2. Aggregate size distribution: (a) Natural and RA coarse aggregates; (b) natural and RA fine aggregates. 
Fine and coarse recycled aggregate presented a nominal maximum size of 4.8 and $25 \mathrm{~mm}$, respectively. As the natural and RA coarse aggregates are obtained through an industrialized process, the granulometric size distribution behaviour, shown in Figure 2, presents a similar curve. The same does not happen, however, with the natural fine aggregates because it is available in nature and the one obtained with RA goes through an industrial improvement process and, this way, it is very difficult to get both curve close.

The physical characterization as well as aggregate size distribution was determined using the Brazilian standard NBR 7211 [18]. The stone fraction of the concrete and demolition waste used to produce aggregates investigated in the research is showed in Table 2 and it was determined as the average composition of two CDW samples.

Table 2. Composition of the stone fraction of CDW sample.

\begin{tabular}{cc}
\hline Material & Average Value (\%) \\
\hline Cement mortar & 23.60 \\
\hline Concrete & 14.64 \\
\hline Ceramic & 35.50 \\
\hline Rocks & 14.10 \\
\hline Sand & 8.00 \\
\hline Other & 4.16 \\
\hline Total & 100 \\
\hline
\end{tabular}

\subsection{Concrete Mixtures and Mechanical Characterization Tests}

To produce the concretes with fine and coarse aggregates from RA, the following methodology was adopted:

RAC with fine aggregates from RA;

Use of Ordinary Portland Cement PC-II-F;

Use of natural quartz coarse aggregate with a maximum size of $25 \mathrm{~mm}$;

Replacement of natural sand by $50 \%$ and $100 \%$ in weight of fine recycled aggregate

RAC with coarse aggregates from RA

Use of Ordinary Portland Cement PC-II-F;

Use of natural fine aggregate with a maximum size of $4.8 \mathrm{~mm}$;

Replacement of natural quartz coarse aggregate by $50 \%$ and $100 \%$ in weight of coarse recycled aggregate; and

Tables 3 and 4 exhibit the concrete mixture prepared using fine and coarse aggregate from RA, respectively.

Table 3. RAC with fine aggregate from RA.

\begin{tabular}{ccccccc}
\hline Ref. & w/c & C (kg) & FA (kg) & CA (Kg) & W (kg) & FRA (kg) \\
\hline $\begin{array}{c}1: 1.58: 2.99 \\
(\mathrm{RCM})\end{array}$ & 0.50 & 5.40 & 8.54 & 16.14 & 2.70 & - \\
\hline $\begin{array}{c}1: 0.79: 0.79: 2.99 \\
\text { (RAC50) }\end{array}$ & 0.50 & 5.79 & 4.57 & 17.31 & 2.90 & 4.57 \\
\hline $\begin{array}{c}\text { 1:0:1.58:2.99 } \\
\text { (RAC100) }\end{array}$ & 0.50 & 5.79 & - & 17.31 & 2.90 & 9.14 \\
\hline
\end{tabular}

$\mathrm{RCM}=$ Reference concrete mixture, $\mathrm{RAC} 50=$ Concrete with $50 \%$ of FRA, RAC100 $=$ Concrete with $100 \%$ of FRA, $\mathrm{C}=$ Cement, $\mathrm{FA}=$ Fine aggregate, $\mathrm{CA}=$ Coarse aggregate, $\mathrm{W}=$ Water, FRA = Fine recycled aggregate. 
Table 4. RAC with fine coarse aggregate from RA.

\begin{tabular}{ccccccc}
\hline Ref. & w/c & C (kg) & FA (kg) & CA (Kg) & W (kg) & CRA (kg) \\
\hline $\begin{array}{c}1: 1.58: 2.99 \\
(\mathrm{RCM})\end{array}$ & 0.50 & 5.40 & 8.54 & 16.14 & 2.70 & - \\
\hline $\begin{array}{c}1: 1.58: 1.49: 1.49 \\
(\text { RAC50) }\end{array}$ & 0.50 & 5.79 & 9.14 & 8.66 & 2.90 & 8.66 \\
\hline $\begin{array}{c}1: 1.58: 0: 2.99 \\
\text { (RAC100) }\end{array}$ & 0.50 & 5.79 & 9.14 & - & 2.90 & 17.31 \\
\hline
\end{tabular}

RCM $=$ Reference concrete mixture, RAC50 = Concrete with 50\% of FRA, RAC100= Concrete with 100\% of FRA, $\mathrm{C}=$ Cement, $\mathrm{FA}=$ Fine aggregate, $\mathrm{CA}=$ Coarse aggregate, $\mathrm{W}=$ Water, $\mathrm{CRA}=$ Coarse recycled aggregate .

To prepare RAC mixtures, coarse aggregates were saturated before its use. This process was done by placing the aggregates submerged in water for 15 (fifteen) minutes. This period was determined by making several measurements of a predetermined mass of the aggregate at different time intervals in which it remained submerged. When his weight no longer increased from a previous measurement to the next measurement, it was assumed that his ability to absorb water had reached its limit [19]. This procedure is necessary to avoid that the coarse aggregate, due to its high absorption rate, absorbs part of the water used in the preparation of the concrete. For the reference concrete made with usual fine and coarse aggregate this procedure was not performed.

To access concrete's mechanical properties, destructive tests were performed-compression and tension tests—as well as non-destructive ones—ultrasonic pulse and sclerometer tests. Compressive and tensile strengths were obtained through 120 concrete cylindrical specimens (100 $\mathrm{mm}$ in diameter and $200 \mathrm{~mm}$ in height) tests -60 for each of them. For each type of test performed, 15 specimens were made in RAC with $50 \%$ of aggregate replacement and 15 were made in RAC with $100 \%$ of aggregate replacement, for each type of recycled aggregates investigated-fine and coarse. Concrete cylindrical specimens were all prepared in accordance to the Brazilian standard NBR 5738 [20].

Concrete compressive strength was determined by uniaxial compression tests of cylindrical specimens, according to the requirements set by the NBR 5739 [21] using a servo-hydraulic press EMIC DL-20000 with $200 \mathrm{kN}$ load capacity. Tensile strength tests were performed using the Brazilian Method according to NBR 7222 [22] using the same servo-hydraulic press.

Ultrasound tests were performed on all specimens according to NBR 8802 [23]. One day before starting the ultrasonic wave speed tests, all specimens were removed from the chamber to surface drying. PUNDIT equipment with a $500 \mathrm{kHz}$ longitudinal transducer frequency was used and placed so that the wave reading was directly transmitted-the most efficient way of transmitting the ultrasonic wave in continuous media [1].

Rebound hammer tests were made according to NBR 7584 [24] and the equipment used provides correlation curves between the rebound value and concrete strength.

\subsection{Concrete Beam Models}

Figure 3 shows the type of bending test performed on reinforced beams made with conventional concrete and RAC using both fine and coarse recycled aggregate. The bending test consists of the application of a monotonic load on a simply supported beam until its failure or until it reaches a pre-established deformation state. This test is well known as the four-point flexural test which is an indirect way to estimate the tensile strength of beams and its more adequate than the three-point test because it produces a pure bending state over a significant area of the specimen. In this aspect, four-point bending is quite similar the tension/compression test. 


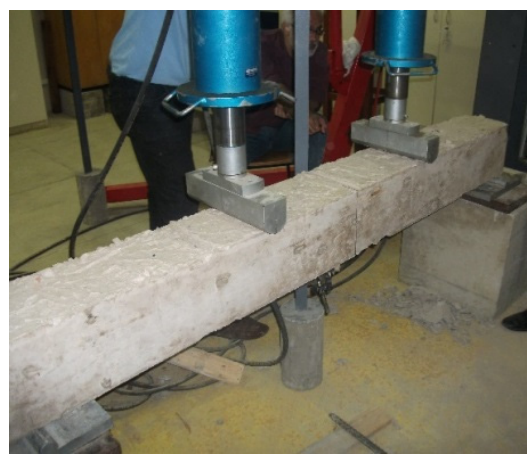

(a) Test overview

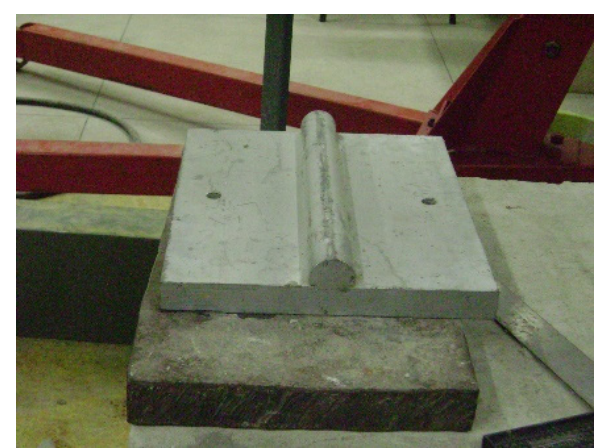

(b) Detail of the roller support

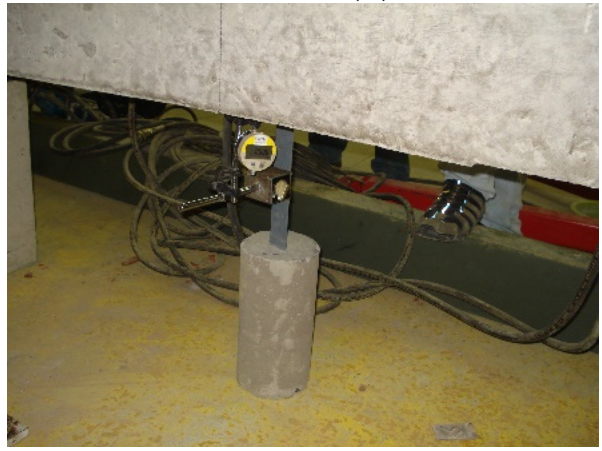

(c) Detail of instrumentation

Figure 3. Four-point beams tests.

Three $2.20 \mathrm{~m}$ reinforced concrete beams with a square cross-section with a side of $20 \mathrm{~cm}$ were prepared, one made with the reference concrete and the other two beams made with concrete with full replacement of both types of recycled aggregates studied. The tests on beams were performed according to Brazilian standard NBR 12142 [25] which recommends the use of elements with square cross section. Tests performed in beams are, in fact, flexural strength test that are often used to measure the tensile flexural strength of concrete. Although this test is usually performed in unreinforced concrete beams, in the current research it was adopted to investigate the bending behaviour of reinforced concrete beams, using concrete produced with different types of aggregates. Steel roller support placed over rigid concrete blocks were installed at both ends of the beam and this scheme avoid displacement/settlement of supports. The only possible displacement allowed is the rotation normal to the plane of the beam.

The choice of making only reinforced concrete beams with $100 \%$ replacement of fine and coarse aggregates by the respective recycled aggregate in the production of concrete was made for two main reasons: (a) average compressive and tensile strengths of concrete made with $100 \%$ recycled fine aggregate were higher than those value for the reference concrete and (b) even if for the replacement of coarse aggregate in a percentage of $50 \%$ the increase in the average mechanical strengths of the concrete were better than those obtained for the percentage of $100 \%$ replacement, the research sought to investigate an extreme situation with a concrete made with only recycled coarse aggregate, in which the strength of the aggregate was less than the strength of the cement matrix that surrounds it, which is not common situation in concretes with moderate compressive strengths. In addition, there were also budget restrictions that limited the scope of laboratory tests performed.

All beams were designed to avoid the sudden non-ductile shear failure and a balanced condition was imposed to perform longitudinal reinforcement calculation and detailing. Reinforcement of all beam were similar-three bars of $10 \mathrm{~mm}$ diameter were extended to cover the whole span in the positive bending moment region and two bars of $6.3 \mathrm{~mm}$ were used in compression region along the entire length of the beam. Flexural reinforcement ratio for all beams tests was $0.7 \%$, which provides a failure governed by the tensile reinforcement 
yielding rather than by concrete crushing. For shear reinforcement, $6.3 \mathrm{~mm}$ diameters stirrups spaced at $17 \mathrm{~cm}$. For both type of reinforcement, Brazilian grade 50 steel with nominal tensile strength of $500 \mathrm{MPa}$ was used.

This study aims to investigate the mechanical response of RAC on both maximum load capacity, displacements, and also evaluate the flexural strengths of the beams tested. Vertical displacements at mid-span were measured using high precision linear variable differential transformer-LVDT-located as indicated in Figure 3c.

\section{Results and Discussion}

\subsection{Ultrassonic Pulse Velocity (UPV) Tests}

UPV tests were performed with the stand scheme showed in Figure 4 in which the direct transmission was used. Direct transmission is adequate because the maximum energy propagates orthogonally to the face of the transmitting transducer (PUNDIT 6 equipment with transducer of $54 \mathrm{kHz}$ and resolution of $0.1 \mu \mathrm{s})$.

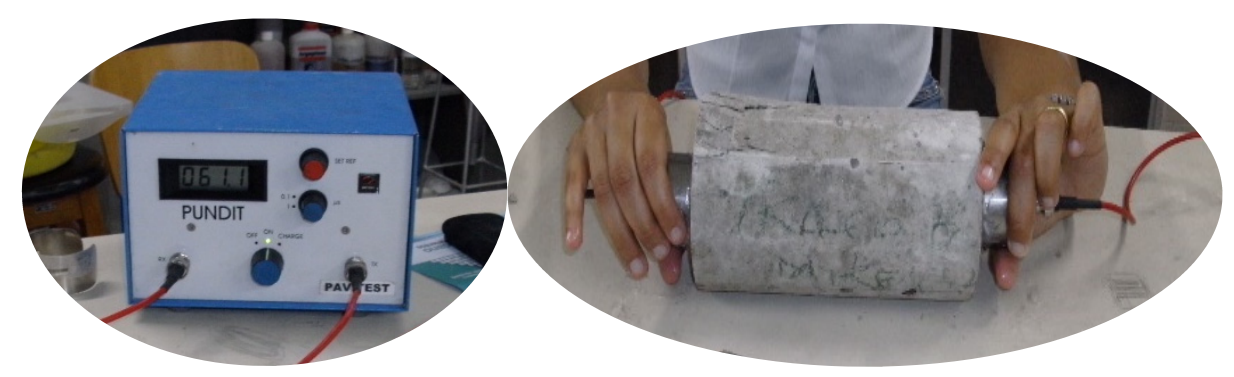

Figure 4. UPV test equipment and stand scheme.

Table 5 summarizes the results of ultrasonic pulse velocity tests performed in all concrete cylindrical specimens. Average UPV values indicated in this table were obtained for a sample of 15 results for each concrete studied and the coefficient of variation associated was very low. Taking into account that the higher the coefficient of variation, the greater the level of dispersion around the mean, the results obtained indicated that concrete quality was excellent for all concrete mixtures studied.

Table 5. Ultrasonic pulse velocity test results.

\begin{tabular}{cccc}
\hline \multirow{2}{*}{ Concrete } & \multicolumn{3}{c}{ UPV } \\
\cline { 2 - 4 } & Average (m/s) & St. Dev. $(\mathbf{m} / \mathbf{s})$ & CV (\%) \\
\hline RCM & 4.56 & 0.17 & 6.25 \\
\hline RAC-F50 & 4.54 & 0.09 & 2.20 \\
\hline RAC-F100 & 4.17 & 0.11 & 2.90 \\
\hline RAC-G50 & 3.98 & 0.09 & 2.25 \\
\hline RAC-G100 & 3.20 & 0.14 & 4.31 \\
\hline
\end{tabular}

RCM $=$ Reference concrete mixture, RAC-G50 = Concrete with 50\% of CRA, RAC-G100 = Concrete with 100\% of GRA, RAC-F50 = Concrete with $50 \%$ of FRA, RAC-F100 $=$ Concrete with $100 \%$ of FRA CV $=$ Coefficient of variation.

Additionally, it can be observed that for the RACs, except those produced with 50\% of fine aggregate replacement, exhibited slow UPV when compared with the reference concrete mixture. This behavior can be explained by the higher density than concrete made with natural aggregates present comparing with those produced with recycled coarse aggregates, thus generating higher speeds. The concretes made with coarse recycled aggregates exhibited the lowest values of ultrasonic wave speeds and it is even decreasing with the increase of the replacement. This happens due to the lower density of the recycled aggregates, thus interfering in the propagation speed of the ultrasonic waves. For RAC- 
G100 it was observed a decrease close to $30 \%$ in UPV, the same behaviour observed by other researchers that reported a decrease of about 5\% in UPV with 50\% replacement of fine aggregate from RA [26-28].

\subsection{Compression and Tension Split Strength Tests}

Compressive strength test results are indicated in Table 6. It is possible to observe from this table that, among the studied RACs, the one that presented the best performance in terms of compressive strength was that produced with $100 \%$ recycled fine aggregate. Oppositely, the RACs produced with recycled coarse aggregates did not show the same behavior and, when the compressive strength of concrete made with $100 \%$ recycled coarse aggregate is compared with the reference concrete, a decreasing about 35\% was observed. This can be explained based on the RAC microstructure. RAC has an additional interfacial transition zone (ITZ) between the aggregate and the old mortar attached (i.e., old ITZ) to the surface of recycled concrete aggregates [29].

Table 6. Mechanical test results.

\begin{tabular}{ccc}
\hline Concrete & Average $\mathbf{f}_{\mathbf{c}}(\mathbf{M P a})$ & Average $\mathbf{f}_{\text {st }}(\mathbf{M P a})$ \\
\hline RCM & $27.0 \pm 1.23$ & $2.90 \pm 0.23$ \\
\hline RAC-F50 & $25.7 \pm 1.42$ & $3.30 \pm 0.27$ \\
\hline RAC-F100 & $28.0 \pm 1.36$ & $3.51 \pm 0.24$ \\
\hline RAC-G50 & $21.49 \pm 2.00$ & $2.94 \pm 0.35$ \\
\hline RAC-G100 & $17.49 \pm 0.99$ & $2.30 \pm 0.32$ \\
\hline
\end{tabular}

ITZ is generally regarded as the weak link in concrete. Therefore, the presence of an additional ITZ in RAC leads to a lower value of compressive strength [30]. Moreover, because of the porous nature of the old mortar attached to the surface of recycled concrete aggregates, the ITZ between the old and new mortar (new ITZ) with low compressive strength, and it forms another weak link in the concrete, which, in turn, results in a lower $\mathrm{f}_{\mathrm{cm}}[31]$.

According to previous researches on RAC and natural aggregate concrete (NAC), the splitting tensile $\left(f_{s t}\right)$ strength of RAC is generally lower than those of NAC with the same concrete mix [32-34]. Other researchers reported that RAC with full replacement of coarse aggregate by RA presented a decrease in tensile strength close to $23 \%$ [35-37].

\subsection{Four-Point Beam Tests}

Failure profile for all reinforced concrete beams tested is shown in Figure 5. The examination of this figure identifies the difference in behaviour at failure, with the concrete compressed block of the RAC-G100 beam failed in compression before the most expressive cracking process in the tensioned region of the beam has manifested itself, situation diametrically opposite to what was observed with the reference beam. This happened due to the low compressive strength of the coarse recycled aggregate used when compared to natural coarse aggregate, which significantly interfered in the modification of the beam failure profile.

For the beam made with RAC with fine aggregate, there is little difference in behaviour at the moment of failure when compared to the reference beam. The cracks in the tensioned part and the crushing of the concrete in the compressed part presented a similar profile. It has been seen previously that from compressive strength, concrete with 100\% recycled fine aggregate presented an excellent performance when compared to concrete with conventional fine aggregate. 


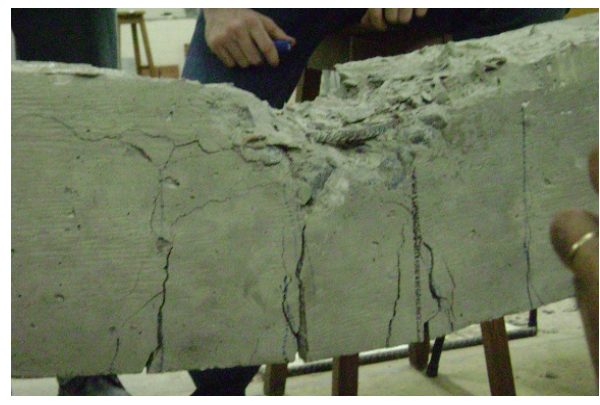

(a) Reference beam

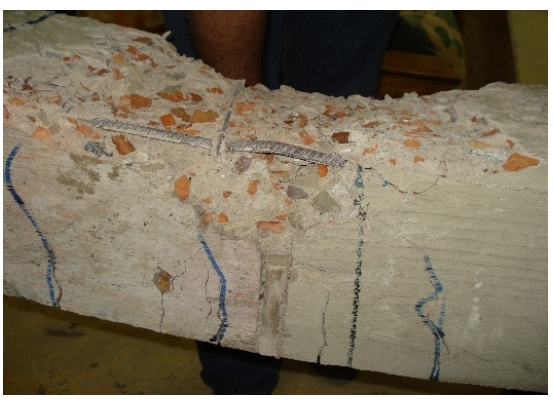

(b) RAC-G100

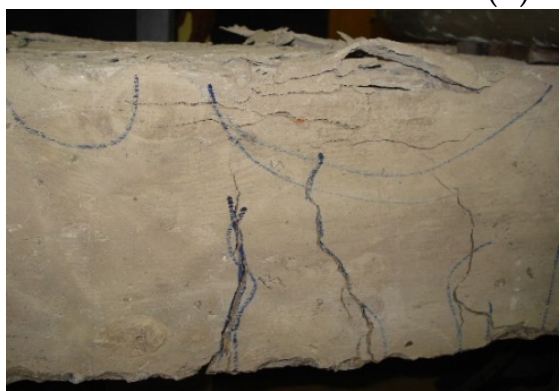

(c) RAC-F100

Figure 5. Overview at failure of beams tested.

Figure 6 shows a graph which typifies the dependence of the force $F$ on the vertical displacement $\delta$. This graph overall characterizes the experimental data obtained from the tests performed. Three different behaviours can be observed in this figure and the beam produced with RAC-G100 is the one that presented the greatest discrepancy when compared to the RCM beam. This shows that the beam made with RAC-G100 proved to be less efficient to the flexural behaviour, an aspect that validates the other experimental results performed.

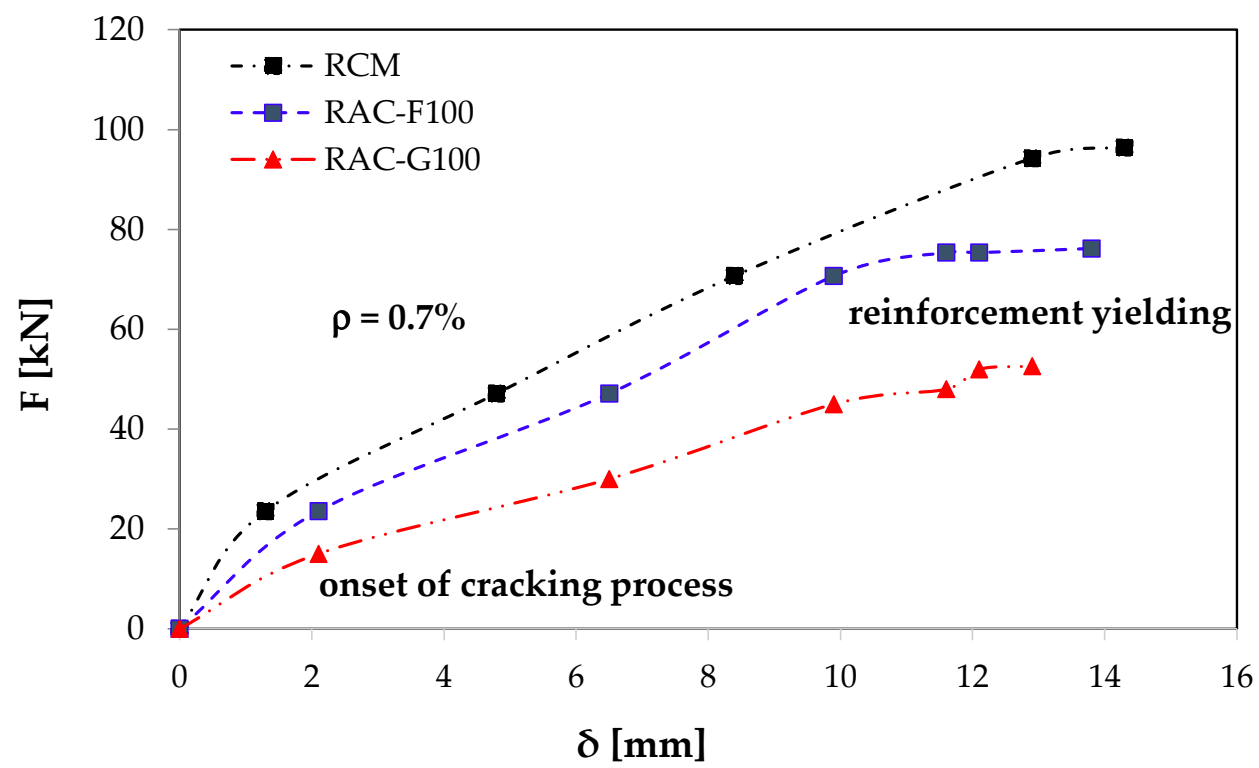

Figure 6. Force $(\mathrm{F})$ versus displacement $(\delta)$ curves.

The shape of the load mod-span displacement showed in Figure 6 indicates, also, a linear behaviour until de failure, except for the first stage of the RCM beam which presented a slight change in the slope of the F vs. $\delta$ curve, an aspect that indicates the beginning the 
begin of beam cracking process. The same behaviour was not observed for RAC's beam which means that those beams presented a very brittle behavior.

The maximum load and displacement are reported in Table 7, separately for each beam tested. It can be seen that the load capacity was decreased with the amount of recycled aggregate being the less one obtained with the full coarse aggregate replacement which presented a failure load close $55 \%$ of the RCM beam in spite small differences in displacements values have been observed. It means that the overall behaviour of beams with recycled aggregates was not very affected because the reinforcement controls the flexural performance of RC beams [38]. Moreover, the cracking profile during the tests showed to be dependent on the type of RAC used [39].

Table 7. Flexural tests of the experimental results.

\begin{tabular}{ccc}
\hline Specimen & Maximum Load (kN) & Maximum Displacement (mm) \\
\hline RCM-Beam & 94.25 & 12.95 \\
\hline RAC-F100 Beam & 81.68 & 12.25 \\
\hline RAC-G100 Beam & 52.10 & 12.10 \\
\hline
\end{tabular}

\section{Conclusions}

The following conclusions can be drawn from the results of tests performed:

Compressive strength ratios between RACs and NACs indicated the following values: (a) 0.89 for RAC-F50; (b) 1.04 for RAC-F100; (c) 0.80 for RAC-G50; and (d) 0.64 for RAC-G100;

Compressive mechanical tests results indicate that, unless those related with RAC made with full coarse usual aggregate substitution, all RACs investigated exhibited a good performance in terms of compressive strength compared to conventional concrete. This observation highlights the potential for recycled aggregates is substitution of usual aggregates without significant loss of performance;

When one observes tensile strength ratios of RAC and NAC the following results were obtained: (a) 1.14 for RAC-F50; (b) 1.21 for RAC-F100; (c) 1.01 for RAC-G50 and (d) 0.79 for RAC-G100;

Tensile mechanical tests results confirm the excellent behavior of all RACs investigated, even for those related with RAC made with full coarse usual aggregate substitution. The results obtained allow us to conclude that the use of RACs did not exhibit significant changes in the tensile strength of the studied concrete and, in some cases, provided higher values, when compared with NAC;

The same behavior describe above was observed regarding the ultrasonic pulse velocity tests that exhibited expected less ultrasound pulse velocity for RAC with low compressive strengths. It means, that UPV test can be used with confidence for an initial analysis of the quality of RAC in terms of compression strength.

In terms of flexural behavior, RAC made with full replacement of usual coarse aggregates generated an important decrease in beam capacity, an aspect that recommends its uses only in small lengths flexural elements because an adequate performance in terms of service load condition cannot be assured due to the decrease of elastic modulus of the material (inclination of the initial part of the curve in Figure 5). On the other hand, for the RACs with full replacement of usual fine aggregate presented slight changes in the global behavior of the investigated beams and this result encourages its use. 
Author Contributions: All the authors contributed to the development, analysis, writing, and revision of the paper: conceptualization, F.A.N.S., A.C.A. and J.M.P.Q.D.; methodology, F.A.N.S., J.M.P.Q.D., A.C.A. and C.S.V.; validation, A.C.A., C.S.V. and A.G.B.L.; formal analysis, A.C.A., J.M.P.Q.D. and A.G.B.L.; investigation, F.A.N.S. and A.C.A.; writing-original draft preparation, F.A.N.S., J.M.P.Q.D., A.C.A., A.G.B.L. and C.S.V.; writing-review and editing, F.A.N.S., J.M.P.Q.D., A.C.A., A.G.B.L. and C.S.V.; supervision, F.A.N.S., J.M.P.Q.D. and A.G.B.L. All authors have read and agreed to the published version of the manuscript.

Funding: This research received no external funding.

Institutional Review Board Statement: Not applicable.

Informed Consent Statement: Not applicable.

Data Availability Statement: New data were created or analyzed in this study. Data will be shared upon request and consideration of the authors.

Acknowledgments: This work was supported by Base Funding-UIDB/04708/2020 and Programmatic Funding-UIDP/04708/2020 of the CONSTRUCT-Instituto de I\&D em Estruturas e Construçõesfunded by national funds through the FCT/MCTES (PIDDAC).

Conflicts of Interest: The authors declare no conflict of interest.

\section{References}

1. Ozbakkaloglu, T.; Gholampour, A.; Xies, T. Mechanical and durability properties of recycled aggregate concrete, effect of recycled aggregate properties and content. J. Mater. Civil Eng. 2018, 30, 04017275. [CrossRef]

2. Kisku, N.; Joshi, H.; Ansari, M.; Pandra, S.K.; Nayak, S.; Dutta, C. A critical review and assessment for usage of recycled aggregate as sustainable construction material. Constr. Build. Mater. 2017, 131, 721-740. [CrossRef]

3. Torgal, F.P.; Jalali, S. Construction and Demolition (CED) Wastes. Eco-Efficient Construction and Building Materials; Springer: London, UK, 2011.

4. Eurostat, Environment and Energy. Generation and Treatment of Waste. 2010. Available online: http:/ / ec.europa.eu/eurostat (accessed on 25 February 2021).

5. Hafez, H.; Kurda, R.; Al-Hadad, B.; Mustafa, R.; Ali, B. A Critical Review on the Influence of Fine Recycled Aggregates on Technical Performance, Environmental Impact and Cost of Concrete. Appl. Sci. 2020, 10, 1018. [CrossRef]

6. Dhir, R.; Paine, K. Value Added Sustainable Use of Recycled and Secondary Aggregates in Concrete. Indian Conc. J. 2010, 84, 7-26.

7. Cho, Y.-H.; Yeo, S.-H. Application of recycled waste aggregate to lean concrete subbase in highway pavement. Can. J. Civ. Eng. 2004, 31, 1101-1108. [CrossRef]

8. Bravo, M.; Brito, J.; Pontes, J.; Evangelista, L. Mechanical performance of concrete made with aggregates from construction and demolition waste recycling plants. J. Clean. Prod. 2015, 99, 59-74. [CrossRef]

9. Song, L.; Liang, D. Lean construction implementation and its implication on sustainability, A contractor's case study. Can. J. Civil Eng. 2011, 38, 350-359. [CrossRef]

10. Makul, N. Cost-benefit analysis of the production of ready-mixed high-performance concrete made with recycled concrete aggregate, A case study in Thailand. Heliyon 2020, 6, e04135. [CrossRef] [PubMed]

11. Ulloa, V.A.; García-Taengua, E.; Pelufo, M.J.; Domingo, A.; Serna, P. New views on effect of recycled aggregates on concrete compressive strength. ACI Mater. J. 2013, 110, 1-10.

12. Atmajayanti, A.T.; Saragih, C.D.; Haryanto, Y. The effect of recycled coarse aggregate (RCA) with surface treatment on concrete mechanical properties. In MATEC Web Conferences, Proceedings of the 4th International Conference on Rehabilitation and Maintenance in Civil Engineering, Solo Baru, Indonesia, 11-12 July 2018; Edp Sciences: Les Ulis, France, 2018; Volume 195, p. 01017.

13. Khatib, J.M. Properties of concrete incorporating fine recycled aggregate. Cem. Concr. Res. 2005, 35, 763-769. [CrossRef]

14. Dilbas, H.; Çakir, Ö.; Şimsek, M. Recycled aggregate concretes (RACs) for structural use, An evaluation on elasticity modulus and energy capacities. Int. J. Civ. Eng. 2016, 15, 247-261. [CrossRef]

15. Thomas, C.; Sosa, I.; Setién, J.; Polanco, J.A.; Cimentada, A.I. Evaluation of the fatigue behavior of recycled aggregate concrete. J. Clean. Prod. 2014, 65, 397-405. [CrossRef]

16. Poon, C.S.; Kou, S.C.; Lam, L. Influence of recycled aggregate on slump and bleeding of fresh concrete. Mater. Struct. 2007, 40, 981-988. [CrossRef]

17. Duan, Z.H.; Kou, S.C.; Poon, C.S. Prediction of compressive strength of recycled aggregate concrete using artificial neural networks. Constr. Build. Mater. 2013, 40, 1200-1206. [CrossRef]

18. NBR 7211 Aggregates for Concrete-Specification; Brazilian Association of Technical Standards; ABNT: Rio de Janeiro, Brazil, 2019.

19. Brito, J.; Bizinotto, M.B.; Ferreira, L. Influence of the pre-saturation of recycled coarse concrete aggregates on concrete properties. Mag. Concr. Res. 2011, 63, 617-627.

20. NBR 5738 Concrete-Procedure for Molding and Curing Concrete Test Specimens; Brazilian Association of Technical Standards; ABNT: Rio de Janeiro, Brazil, 2018. 
21. NBR 5739 Concrete-Compression Test of Cylindrical Specimens; Brazilian Association of Technical Standards; ABNT: Rio de Janeiro, Brazil, 2018.

22. NBR 7222 Concrete and Mortar-Determination of the Tension Strength by Diametrical Compression of Cylindrical Test Specimens; Brazilian Association of Technical Standards; ABNT: Rio de Janeiro, Brazil, 2011.

23. NBR 8802 Hardened Concrete-Determination of Ultrasonic Wave Transmission Velocity; Brazilian Association of Technical Standards; ABNT: Rio de Janeiro, Brazil, 2019.

24. NBR 7584 Hardened Concrete—Evaluation of Surface Hardness by Reflecting Esclerometer-Test Method; Brazilian Association of Technical Standards; ABNT: Rio de Janeiro, Brazil, 2012.

25. NBR 12142 Concrete-Determination of Tension Strength in Flexure of Prismatic Specimens; Brazilian Association of Technical Standards; ABNT: Rio de Janeiro, Brazil, 2010.

26. Cantero, B.; Bravo, M.; Brito, J.; Bosque, I.S.; Medina, C. Mechanical behaviour of structural concrete with ground recycled concrete cement and mixed recycled aggregate. J. Clean. Prod. 2020, 275, 122913. [CrossRef]

27. Saha, A.K.; Majhi, S.; Sarker, P.K.; Mukherjee, A.; Siddika, A.; Aslani, F.; Zhuge, Y. Non-destructive prediction of strength of concrete made by lightweight recycled aggregates and nickel slag. J. Build. Eng. 2020, 33, 101614. [CrossRef]

28. Singh, N.; Singh, S.P. Evaluating the performance of self-compacting concretes made with recycled coarse and fine aggregates using non-destructive testing techniques. Constr. Build. Mater. 2018, 181, 73-84. [CrossRef]

29. Li, W.; Xiao, J.; Sun, Z.; Kawashima, S.; Shah, S.P. Interfacial transition zones in recycled aggregate concrete with different mixing approaches. Constr. Build. Mater. 2012, 35, 1045-1055. [CrossRef]

30. Xie, T.; Gholampour, A.; Ozbakkaloglu, T. Toward the development of sustainable concretes with recycled concrete aggregates, comprehensive review of studies on mechanical properties. J. Mater. Civ. Eng. 2018, 30, 04018211. [CrossRef]

31. Medina, C.; Zhu, W.; Howind, T.; Rojas, M.I.S.; Frías, M. Influence of interfacial transition zone on engineering properties of the concrete manufactured with recycled ceramic aggregate. J. Civ. Eng. Manag. 2015, 21, 83-93. [CrossRef]

32. Behera, M.; Bhattacharyya, S.K.; Minocha, A.K.; Deoliya, R.; Maiti, S. Recycled aggregate from C\&D waste \& its use in concrete-A breakthrough towards sustainability in construction sector: A review. Constr. Build. Mater. 2014, 68, 501-516.

33. Safiuddin, M.; Alengaram, U.J.; Rahman, M.M.; Salam, M.A.; Jumaat, M.Z. Use of recycled concrete aggregate in concrete, a review. J. Civ. Eng. Managm. 2013, 19, 796-810. [CrossRef]

34. Xiao, J.Z.; Li, J.B.; Zhang, C. On relationships between the mechanical properties of recycled aggregate concrete, an overview. Mater. Struct. 2006, 39, 655-664. [CrossRef]

35. Mefteh, H.; Kebaili, O.; Oucief, H.; Berredjem, L.; Arabi, N. Influence of moisture conditioning of recycled aggregates on the properties of fresh and hardened concrete. J. Clean. Prod. 2013, 54, 282-288. [CrossRef]

36. Thomas, C.; Setien, J.; Polanco, J.A.; Alaejos, P.; Sanchez, J.M. Durability of recycled concrete aggregate. Constr. Build. Mater. 2013, 40, 1054-1065. [CrossRef]

37. Wu, K.R.; Chen, B.; Yao, W.; Zhang, D. Effect of coarse aggregate type on mechanical properties of high-performance concrete. Cem. Concr. Res. 2001, 31, 1421-1425. [CrossRef]

38. Younis, A.; Ebead, U.; Suraneni, P.; Nanni, A. Short-term flexural performance of seawater-mixed recycled-aggregate GFRPreinforced concrete beams. Compos. Struct. 2020, 236, 111860. [CrossRef]

39. Fahmy, M.F.M.; Idriss, L.K. Flexural behavior of large-scale semi-precast reinforced concrete T-beams made of natural and recycled aggregate concrete. Eng. Struct. 2019, 198, 109525. [CrossRef] 